\title{
Flora das cangas da Serra dos Carajás, Pará, Brasil: Moraceae
}

\author{
Flora of the canga of the Serra dos Carajás, Pará, Brazil: Moraceae
}

\author{
Sergio Romaniuc-Neto ${ }^{1,3}$, Leandro Cardoso Pederneiras ${ }^{2} \&$ André Luiz Gaglioti $^{1}$
}

\begin{abstract}
Resumo
Este trabalho compreende um tratamento para Moraceae nas cangas da Serra dos Carajás, no estado do Pará. São apresentados descrição, fotografia e comentário para Ficus americana subsp. guianensis, a única espécie registrada na área de cangas.
\end{abstract}

Palavras-chave: clado urticóide, FLONA Carajás, taxonomia, Urticineae.

\begin{abstract}
This paper encompasses a treatment for the Moraceae registered for the canga of Serra dos Carajás, Pará state. Description, photo and comments on Ficus americana subsp. guianensis are presented, the only species of the family recorded in the canga vegetation.
\end{abstract}

Key words: urticalean clade, FLONA Carajás, taxonomy, Urticineae.

\section{Moraceae}

Moraceae Gaudich. agrupa 38 gêneros e cerca de 1.150 espécies, principalmente nas regiões tropicais do mundo, com mais de $50 \%$ dos gêneros representados desde o México até a Argentina (Berg 2001). No Brasil ocorrem 19 gêneros e aproximadamente 205 espécies, destas 68 endêmicas para o país (BFG 2015). As espécies podem ser monoicas ou dioicas, inermes ou armadas, em sua maioria árvores e arbustos, mas também hemiepífitas em algumas espécies de Ficus L. ou ervas para Dorstenia L. A família pode ser reconhecida pela presença de estípulas terminais, livres ou unidas, com laticíferos distribuídos por todas as partes da planta. As folhas são simples, alternas e as inflorescências axilares, bissexuadas ou unissexuadas, racemosas ou cimosas, com flores aclamídeas ou monoclamídeas. Moraceae está representada na vegetação de cangas da Serra dos Carajás por apenas um táxon: Ficus americana subsp. guianensis (Desv. ex Ham.) C.C. Berg., porém uma maior diversidade das espécies da família é listada para as áreas transicionais de vegetação rupestre e florestas de terra firme, em matas baixas e úmidas, próxima a cursos d'água, sendo raras nos capões de mata adjacentes à vegetação de cangas.

\section{Ficus L.}

Árvores ou hemiepífitas, com raízes tabulares ou adventícias. Estípulas terminais completamente amplexicaules, conatas. Folhas com 1 ou 2 glândulas próximas à nervura basal. Inflorescências globosas, urceoladas (figo), brácteas basais (epibrácteas) e ostíolo presentes. Flores estaminadas dispersas entre as flores pistiladas; flores pistiladas sésseis ou pediceladas, estiletes com diferentes tamanhos, estigma inteiro ou bífido; flores galígenas não férteis presentes. Infrutescência com receptáculo carnoso (figo). Fruto aquênio. Para o Brasil são reportadas 83 espécies de Ficus (BFG 2015), somente $F$. americana subsp. guianensis foi encontrada na vegetação de cangas da Serra dos Carajás.

1.1. Ficus americana Aubl. subsp. guianensis (Desv. ex Ham.) C.C. Berg, Blumea 52: 300. 2007.

Fig. 1

Árvores 5-10 m alt. Estípulas 5-9 mm compr., glabras. Lâminas 9-14×4-6 cm, elípticas, ápice agudo a cuspidado, base cuneada, glabras; nervuras secundárias 13-17 pares, formando nervura intramarginal; pecíolos 1,5-3 cm compr., glabros. Figos rosados com máculas vináceas, agrupados nas axilas das folhas ou em braquiblastos

\footnotetext{
${ }^{1}$ Instituto de Botânica - Herbário SP, Avenida Miguel Stéfano 3687, 04301-902, São Paulo, SP, Brasil.

${ }^{2}$ Instituto de Pesquisa do Jardim Botânico do Rio de Janeiro, Rua Pacheco Leão 915, 22460-030, Rio de Janeiro, RJ, Brasil.

${ }^{3}$ Autor para correspondência: sromaniuc@gmail.com
} 
de 1-3 mm compr., ao longo do ramo terminal, 6-8 mm diâm. quando secos, glabros, epibrácteas 2; pedúnculos 2-4 mm compr. Flores estaminadas com 1 estame.

Material selecionado: Canaã dos Carajás, Serra dos Carajás, S11D, 16.III.2009, V.T. Giorni et al. 181 (BHCB); 6.XII.2007, N.F.O. Mota et al. 1062 (BHCB); 29.VI.2013, R.S. Santos et al. 90 (MG); canga da Serra Sul, Corpo A, 26.VI.2009, R.D. Ribeiro 1211 (HCSJ, RB). Parauapebas, Serra Norte, beira de estrada do N4, 22.IV.1970, M.F.F. Silva 2676 (MG); Serra Norte, 11.X.1977, C.C. Berg et al. 468 (MG, RB).

Essa espécie pode ser reconhecida na natureza pelos figos globosos de coloração rosada com máculas vináceas, porém essa característica não é facilmente observada quando secas. A compreensão taxonômica de Ficus americana - com seus diversos sinônimos, subespécies e formas - ainda permanece complexa. Berg (2007) designa cinco subespécies dentro de $F$. americana,

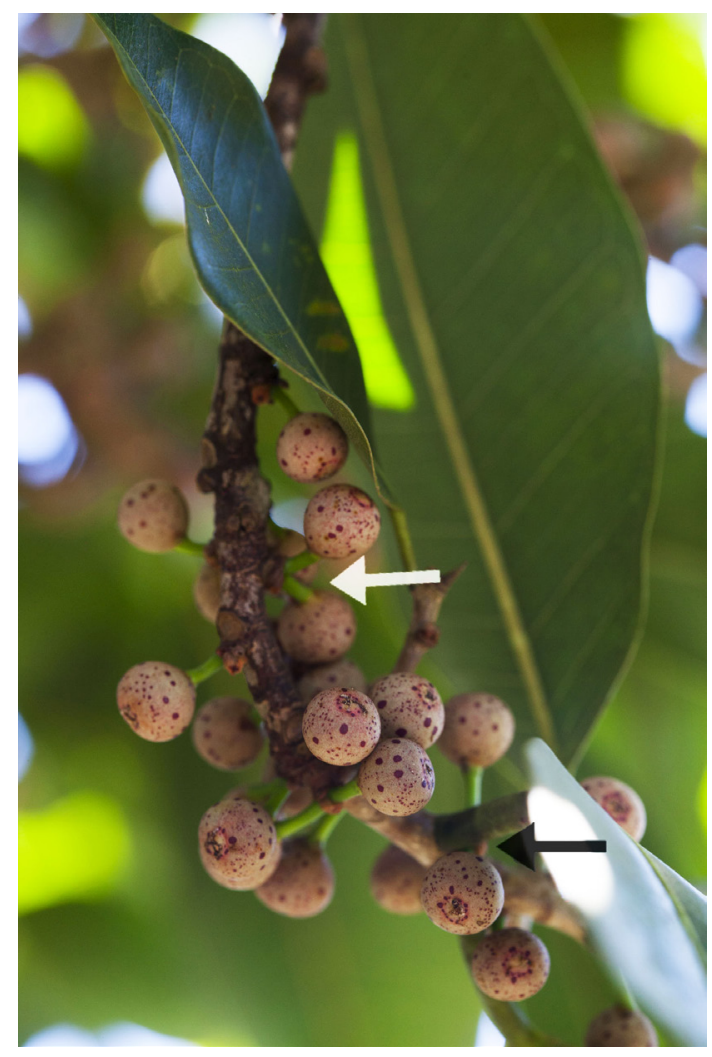

Figura 1 - Ficus americana subsp. guianensis - inflorescências (figos). Seta branca: figos em braquiblastos. Seta preta: figos na axila da folha. Foto: João Marcos Rosa

Figure 1 - Ficus americana subsp. guianensis - inflorescences (figs). White arrow: figs in spurs. Black arrow: figs in the axil of the leaf. Photo: João Marcos Rosa sendo o número de inflorescências por entrenó e o posicionamento dos figos nos ramos (nas axilas das folhas, no ramo logo abaixo da folha, ou em braquiblastos) como caracteres preponderantes desta divisão. Porém, no material analisado para as cangas da Serra dos Carajás, nota-se que todas estas características podem ser encontradas no mesmo indivíduo (eg., Cavalcante 2688, Silva 2676 e Figura 1). Além disso, Aublet (1775) descreve $F$. americana como um táxon que possui figos geminados sem mencionar braquiblastos, semelhante à descrição de $F$. guianensis apresentada por Hamilton (1825). Miquel (1848) foi o primeiro a observar a presença de braquiblastos em $F$. americana, porém Berg (2007) diverge dessa opinião citando apenas figos na axila da folha ou logo abaixo destas. Outras divergências estão nas três entidades dentro de Ficus americana subsp. guianensis (mathewsii-forma, clusiifolia-forma e parkeriana-forma; Berg 2007), que segundo Carauta (1989) e BFG (2015) deveriam ser tratadas como espécies distintas. A variação dos caracteres diagnósticos entre estas espécies e a lacuna do conhecimento taxonômico existente fez com que diversos autores tratassem estes nomes como um complexo de espécies (Berg et al. 1986; Berg 1992; Berg \& Simonis 2000; Berg \& Villavicencio 2004). Assim, concluímos que ainda existe a necessidade de um estudo aprofundado de revisão taxonômica para $F$. americana e suas espécies aliadas, assim como para toda a seção Americanae. Neste tratamento, manteremos Ficus americana subsp. guianensis, seguindo a circunscrição proposta por Berg (2007). Nas cangas da Serra dos Carajás, F. americana subsp. guianensis foi registrada apenas na Serra Sul: S11A e S11D e na Serra Norte: N4.

\section{Agradecimentos}

Agradecemos aos curadores dos herbários BHCB, IAN, MG e RB, a disponibilização de material para a análise. Ao Dr. Pedro Viana e Dra. Ana Maria Giulietti, coordenadores do projeto "Flora de Carajás", o convite. Ao projeto objeto do convênio MPEG/ITV/FADESP (01205.000250/2014-10) e aos projetos CNPq /CAPES/ PROTAX (proc. 440502/2015-2), FAPESP/AP.R (proc. 2016/50385-4), FAPERJ, E-26/202.862/2016 e $n^{\circ} E-26 / 202.863 / 2016$.

\section{Referências}

Aublet JBCF (1775) Histoire des Plantes de la Guiane francoise: rangées suivant la méthode sexuelle, avec plusieurs mémoires sur différens objects intéressans, 
relatifs à la culture \& au commerce de la Guiane Françoise, \& une notice des plantes de l'Isle-deFrance. Pierre-François Didot jeune, London and Paris. Pp. 951-952.

Berg CC (1992) Moraceae. In: Görts-Van Rijn ARA \& Jansen-Jacobs MJ (eds.) Flora of the Guianas. Serie A: Phanerogams. Koeltz Scientific Books, Koenigstein. Pp. 10-92.

Berg CC 2001. Moreae, Artocarpeae and Dorstenia (Moraceae). With introductions to the family and Ficus and with additions and corrections to Flora Neotropica Monograph 7. Flora Neotropica Monograph. Vol. 83. The New York Botanical Garden, New York. 346p.

Berg CC (2007) Proposals for treating four species complexes in Ficus subgenus Urostigma section Americanae (Moraceae). Blumea 52: 295-312.

Berg CC \& Simonis JE (2000) Moraceae. In: Riina $\mathrm{R}$ (ed.) Flora de Venezuela. Fundación Instituto Botánico de Venezuela "Dr. Tobías Lasser", Caracas. Pp. 5-189.
Berg CC, Vázquez-Avila M \& Kooy F (1986) Ficus species of Brazilian Amazonia and the Guianas. Acta Amazonica 14 (suppl):159-194.

Berg CC \& Villavicencio X (2004) Taxonomic studies on Ficus (Moraceae) in the West Indies, extraAmazonian Brazil and Bolivia. Ilicifolia 5: 1-173.

BFG - The Brazil Flora Group (2015) Growing knowledge: an overview of seed plant diversity in Brazil. Rodriguésia 66: 1085-1113.

Carauta JPP (1989) Ficus (Moraceae) no Brasil: conservação e taxonomia. Albertoa 2: 1-365.

Hamilton G (1825) Prodromus Plantarum Indiae Occidentalis hucusque Cognitarum tam in oris Americae Meridionalis, quam in insulis Antillicis sponte crescentium, aut ibi diuturne hospitantium, nova genera et species hactenus ignotas complectens. Treuttel et Würtz, London and Paris. Pp. 62.

Miquel FAW (1848) Prodromus monographie Ficuum. London Journal of Botany 7: 64-78, 109-16, 221$236,425-471$.

\section{Lista de exsicatas}

Berg CC 468 (1.1). Giorni VT 181 (1.1). Mota NFO 1062 (1.1). Ribeiro RD 1211 (1.1). Santos RS 90 (1.1). Silva MFF 2676 (1.1).

Editora de área: Dra. Daniela Zappi Artigo recebido em 11/12/2017. Aceito para publicação em 11/04/2018. This is an open-access article distributed under the terms of the Creative Commons Attribution License. 
